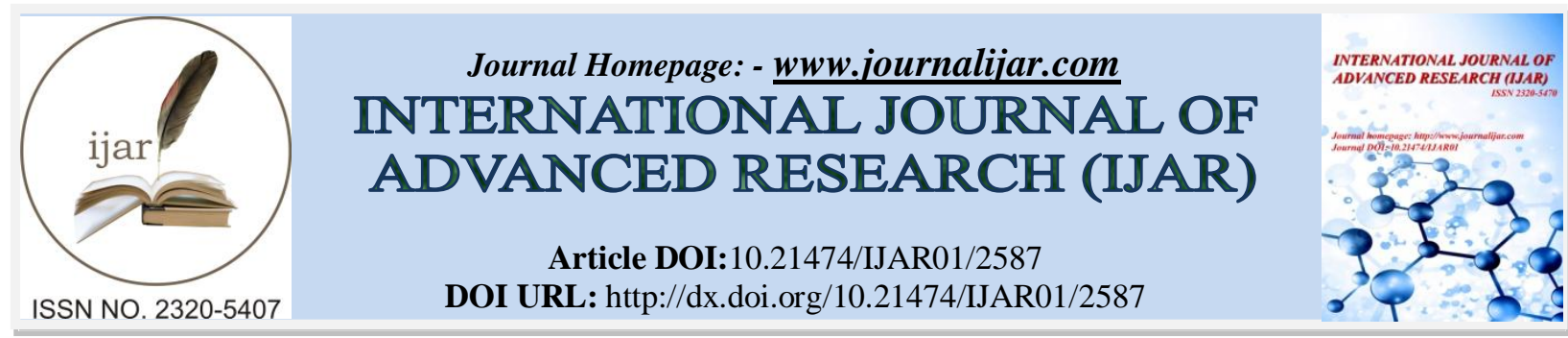

RESEARCH ARTICLE

\title{
TREATMENT MODALITIES AND THROMBOCYTOPENIA AFFECT MORTALITY IN ELDERLY ICU PATIENTS- OBSERVATIONAL STUDY IN TERTIARY CARE HOSPITAL IN NORTHERN INDIA
}

\author{
Afshan Shabir ${ }^{1}$ and Muzaffar Maqbool ${ }^{2}$. \\ 1. Registrar Department of Medicine Government Medical College Srinagar. \\ 2. Assistant Professor Department of Medicine Government College Srinagar.
}

\section{Manuscript Info}

\section{Manuscript History}

Received: 27 October 2016

Final Accepted: 25 November 2016

Published: December 2016

\section{Key words:-}

Geriatrics, renal replacement therapy, Intensive Care Unit outcomes, inotropes, mechanical ventilation, tracheostomy, thrombocytopenia

\section{Abstract}

Ageing is a global phenomenon and number of patients admitted to Intensive Care Units (ICU) is increasing steadily. Number of studies assessing outcome in elderly South Asian patients in ICU is limited. Further research is necessary in this area so that the there is no bias in admitting the elderly in ICU especially in resource constrained units.

Objective: Examine age-related difference in outcomes of ICU treatment in the elderly. Materials and Methods: A retrospective observational study was conducted in 100 patients admitted in a medical ICU (MICU) of a secondary care hospital over one year study period from September 2015 to September 2016. A clinical database was collected which included age, sex, SOFA (Sequential Organ Failure Assessment) scores, patient outcome, average length of ICU stay, admitting diagnosis and the treatment modalities used in ICU including mechanical ventilation (invasive and non-invasive), inotropes, renal replacement therapy (RRT), and tracheostomy. We divided patients into two groups i.e. less than 65 years (Control group) and greater than 65 years (Geriatric age group). Results: The observed overall ICU mortality rate in the study population was $27 \%$. The overall mortality between the control and geriatric age group was not statistically significant $(\mathrm{P}>0.05)$. Mechanical ventilation $(\mathrm{P}=0.003$, odds ratio $[\mathrm{OR}]=0.473,95 \%$ confidence interval $[\mathrm{CI}]=0.290$ $0.743)$ and use of inotropes $(\mathrm{P}=0.000, \mathrm{OR}=8.500,95 \% \mathrm{CI}=2.848$ 25.370), Renal Replacement therapy $(\mathrm{P}=0.049, \mathrm{OR}=3.343,95 \% \mathrm{CI}=$ $0.955-11.707)$ and platelet count $\angle 150(\mathrm{P}=0.000, \mathrm{OR}=5.630,95 \% \mathrm{CI}=$ 2.362-13.420)were found to be predictors of mortality in elderly population. On multivariate analysis, inotropic support was found to be an independent modality predicting ICU mortality in the geriatric age group $(\beta$ coefficient $=1.221, \mathrm{P}=0.000)$. SOFA score $11.77 \pm 2.93$ was associated with higher mortality. Non-invasive ventilation (NIV) is associated with better outcome in elderly as compared to invasive ventilation $\quad(\mathrm{P}=0.002, \quad \mathrm{OR}=0.154, \quad 95 \% \quad \mathrm{CI}=0.042-0.567$.Conclusion: Intensive Care Unit mortality rates increased in the geriatric population requiring mechanical ventilation, inotropes, RRT and platelet count $<150$ during ICU stay. Only inotropic support could be identified as independent risk factor formortality. Thrombocytopenia is a simple and readily available marker for mortality which is independent of and complementary to established severity of disease indices in the elderly. 


\section{Introduction:-}

Population ageing is a global phenomenon. [1] People aged over 65 years is the fastest growing segment of population worldwide [1]. It is predicted that by 2050, the elderly population of the world will exceed that of the young [2]. As the population demographics are changing, there is an increase in the number of geriatric patients being admitted to Intensive Care Units (ICUs). [2] The elderly patients comprise between $26 \%$ and $51 \%$ of ICU admissions. [3] This emphasizes the need for continued research on outcomes of intensive care for the elderly, especially in the medium income South-East Asian countries with a growing elderly population.Various studies have proposed for different predictors of mortality in geriatric ICU patients. [1],[2],[3] Multiple studies on the ICU outcomes of the geriatric population in the high income countries is available, but the studies on outcomes in ICUs of medium income countries like India is scarce. This is primarily due to overburdened healthcare with less resources. The aim of the study was to examine the age-related difference in mortality in medical ICU and ICU treatment modalities affecting mortality in elderly patients $>65$ years of age in a tertiaary care Indian ICU. We also assessed thrombocytopenia as a predictor of mortality in the elderly.

\section{Materials and Methods:-}

We first obtained approval from the hospital ethics committee, then a retrospective observational study was conducted in a medical ICU (MICU) of a tertiary care hospital, in Northern India. Case notes of a total of 100 consecutive patient admitted to medical ICU from September 2015 to September 2016were assessed. The criteria for admission is decided by the admitting intensivist based on the clinical condition and functional status of the patient. Primarily patients are admitted from Medicine, however patients are also admitted from other specialties if no beds are available in Surgical ICU. No patient is refused admission to the ICU based on age and no treatment option is restricted to a specific group of patients during the ICU stay.48patients with incomplete records were excluded. Data collected included age, sex, admitting diagnosis, SOFA (Sequential Organ Failure Assessment) scores at the time of ICU admission, average length of stay, treatment modalities and the patient outcome. The average length of stay (ALOS) was calculated from the time of admission in ICU to discharge from ICU or death. Data collected for treatment modalities used during the ICU stay included use of mechanical ventilation (invasive or non-invasive), inotropes, renal replacement therapy and tracheostomy. The patients were divided into two groups: <65 years as Control group (Group C) and $>65$ years as Geriatric age group (Group G). Statistical Data was expressed as mean \pm standard deviation and percentages. Continuous variables were evaluated using Student's t-test and categorical variables using Chi-square test. Patient characteristics, odds ratio (OR) and confidence intervals $(\mathrm{CI})$ were calculated by logistic regression analysis to identify independent risk factors and control confusion effects. Significant variables in univariate analysis were submitted to logistic regression. Significance probabilities ( $\mathrm{P}$ values) of $<0.05$ were considered statistically significant. Statistical analysis was performed using the IBM SPSS statistics version 17.0.

\section{Results:-}

During the study period, a total of 148 patients were admitted in the ICU. 100 consecutive patient's records were assessed. The medical records of 48 patients were found to be incomplete, and these patients were excluded from the study. Of the 100 patients, 51 (51\%) were in Group C, while $49(49 \%)$ were in Group G. The average age in Group $\mathrm{C}$ was $30 \pm 11.76$ years while in Group G was $71 \pm 9$ years. Male to female ratio in Group C was 24(24\%): 25 (25\%) and in Group G was 26 (26\%): 25 (25\%). No statistical difference was observed in the demographic profile of two groups $(\mathrm{P}>0.05)$ [Table 1 and 2]. The admitting diagnosis of patients is as shown in [Figure 1]. The maximum admissions were secondary to sepsis followed by poisoning. Our study patient was sicker as these were medical patients and evidenced by significantly higher SOFA score of $5.37 \pm 2.85$ in survivors and $11.77 \pm 2.93$ in nonsurvivors. The average duration of ICU stay in survivors was $12.14 \pm 2.52$ days and in non-survivors $5.709 \pm 6.16$ days.

Table 1:- Age versus mortality

\begin{tabular}{|l|l|l|}
\hline & $<65$ & $\geq 65$ \\
\hline Total patients, $\mathrm{n}(\%)$ & $51(51)$ & $49(49)$ \\
\hline Mortality, n (\%) & $17(17)$ & $27(27)$ \\
\hline Shifted to ward & $34(34)$ & $22(22)$ \\
\hline
\end{tabular}


Figure 1:- Admitting diagnosis to MICU

\begin{tabular}{|l|l|l|l|l|}
\hline \multicolumn{2}{|l}{} & Outcome & & Total \\
\cline { 3 - 5 } \multicolumn{2}{|l}{} & $\begin{array}{l}\text { Shifted } \\
\text { to ward }\end{array}$ & Died & \\
\hline Diagnosis & & & & \\
\hline & AIDP & 6 & 0 & $6 \%$ \\
\hline & $\begin{array}{l}\text { ARDS } \\
\text { AKI/CKD }\end{array}$ & 2 & 0 & $2 \%$ \\
\hline & $\begin{array}{l}\text { CAP } \\
\text { T1RF }\end{array}$ & 6 & 1 & $7 \%$ \\
\hline & $\begin{array}{l}\text { COPD } \\
\text { T2RF }\end{array}$ & 12 & 2 & $14 \%$ \\
\hline & GTCS & 2 & 2 & $4 \%$ \\
\hline & stroke & 1 & 11 & $12 \%$ \\
\hline & $\begin{array}{l}\text { cardiac } \\
\text { causes }\end{array}$ & 3 & 4 & $7 \%$ \\
\hline & poisoning & 12 & 7 & $19 \%$ \\
\hline & surgical & 1 & 1 & $2 \%$ \\
\hline & trauma & 1 & 1 & $2 \%$ \\
\hline & Other & 4 & 0 & $4 \%$ \\
\hline & $\begin{array}{l}\text { sepsis } \\
\text { MODS }\end{array}$ & 5 & 16 & $21 \%$ \\
\hline Total & & 56 & 44 & 100 \\
\hline & & & & \\
\hline
\end{tabular}

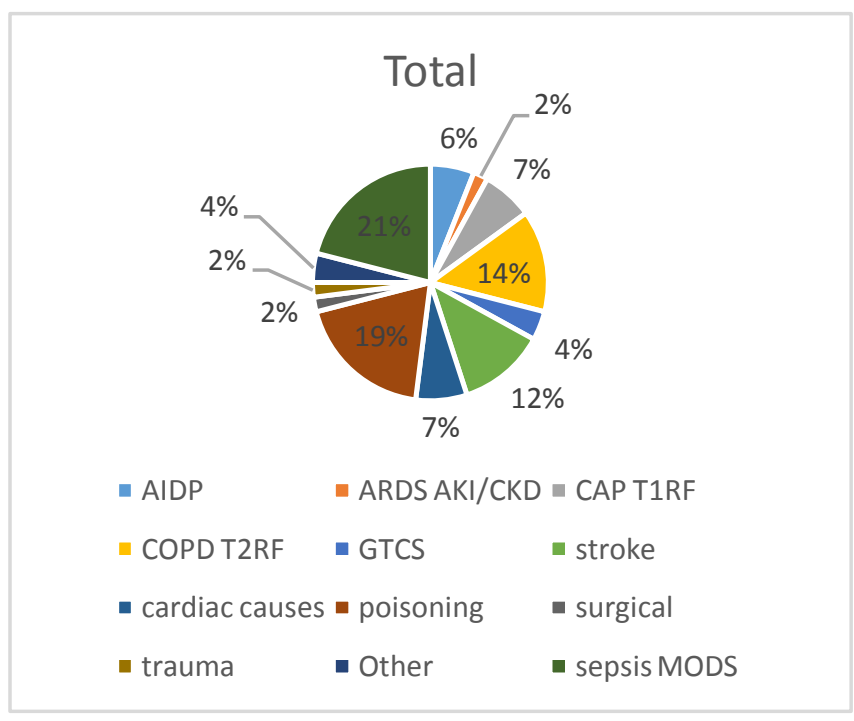

ARDS: Acute Respiratory Distress Syndrome, T1/T2 RF: Type $1 \& 2$ respiratory failure, CAP: Community Aquired Pneumonia,

GTCS: Generalised Tonic Clonic seizures, AKI: Acute Kidney Injury,AIDP: Acute Inflammatory Demyelinating Polyneuropathy,

CKD: Chronic kidney disease, COPD: Chronic Obstructive Pulmonary disease, MODS: Multiple Organ Dysfunction Syndrome

The overall observed ICU mortality was $44 \%$. On statistical analysis, no association was found between mortality and sex ratio preference in both the age groups $(\mathrm{P}>0.05)$. The ICU mortality rate in Group $\mathrm{C}$ was $17 \%$ (17 deaths), while in Group $\mathrm{G}$, was $27 \%$ (27 patients) $(\mathrm{P}=0.276$ ). There was no statistical difference in the frequency of treatment modalities used in two groups in the form of mechanical ventilation, renal replacement therapy, inotropes and tracheostomy $(\mathrm{P}>0.05)$.

Table 2:- Sex versus mortality

\begin{tabular}{|l|l|l|l|l|}
\hline & Shifted to ward (\%) & Died (\%) & Total (\%) & P value \\
\hline Female & 27 & 23 & 50 & \multirow{2}{*}{} \\
\cline { 1 - 3 } Male & 29 & 21 & 50 & \\
\cline { 1 - 3 } Total & 56 & 44 & 100 & \\
\hline & & & & \\
\hline
\end{tabular}

Overall 68 patients $(68 \%)$ required mechanical ventilation. The mortality rate in patients requiring mechanical ventilation was 32\%. 34 patients required ventilatory support in Group C (50\%), of which 13 (38.23\%) expired while 34 patients (50\%) in Group G required ventilatory support, of which $20(58.8 \%)$ expired. The mortality rate was significantly higher in geriatric patients requiring mechanical ventilation than the Group $\mathrm{C}$ patients $(\mathrm{P}=0.003$, $\mathrm{OR}=0.473,95 \% \mathrm{CI}=0.290-0.743$.) [Table 3].

Table 3:- Predictors of mortality in geriatric age group

\begin{tabular}{|l|l|l|l|l|lc|}
\hline & Group C & Group G & P value & Odds ratio & \multicolumn{2}{|c|}{ 95\% confidence interval } \\
$(\%)$ & $(\%)$ & $20(58.8)$ & 0.003 & 0.473 & 0.290 & 0.743 \\
\hline $\begin{array}{l}\text { Invasive } \\
\text { ventilation }\end{array}$ & $13(38.23)$ & 20 . & & & & \\
\hline
\end{tabular}




\begin{tabular}{|l|l|l|l|l|ll|}
\hline Inotropes & $7(63.63)$ & $15(100)$ & 0.000 & 8.500 & 2.848 & 25.370 \\
\hline Tracheostomy & 0 & 0 & 0.259 & 0.397 & 0.076 & 2.070 \\
\hline $\begin{array}{l}\text { Renal } \\
\text { Replacement } \\
\text { therapy }\end{array}$ & $5(62.5)$ & $4(80)$ & 0.049 & 3.343 & 0.955 & 11.707 \\
\hline
\end{tabular}

In total, 26 patients (26\%) required inotropic support during ICU stay. The overall mortality rate for patients on inotropes was $80 \%$. In Group C, 11 patients (11\%) required inotropic support, of which 7 patients (63.63\%) died, while 15 patients (15\%) in Group G required inotropic support, of which 15 patients died (100\%). There was a significant difference in mortality in geriatric and control groups requiring inotropes $(\mathrm{P}=0.000, \mathrm{OR}=8.500,95 \% \mathrm{CI}$ $=2.848-25.370)$.

In our study, 13 patients (13\%) required renal replacement therapy (RRT) and the mortality rate for patients requiring renal replacement was $69.23 \%$. A total of 8 patients $(8 \%)$ in Group C required RRT out of which 5 (62.5\%) expired while 5 patients (5\%) in Group G underwent RRT during their ICU stay, of which 4 died (80\%). Significant difference in mortality was observed in Groups $\mathrm{G}$ and $\mathrm{C}$ requiringRRT in ICU $(\mathrm{P}=0.049, \mathrm{OR}=3.343$, $95 \% \mathrm{CI}=0.955-11.707)$.

Tracheostomy was done in 7 patients (7\%) during the study period. The mortality rate for tracheostomized patients was $0 \%$. In Group C, 6 patients $(6 \%)$ required tracheostomy of which $0(0 \%)$ died while 1 patient (1\%) in Group G were tracheostomized during ICU stay, of which 0 died $(0 \%)$. The mortality rate did not differ significantly in Group $\mathrm{G}$ and $\mathrm{C}$ patients requiring tracheostomy $(\mathrm{P}=0.259, \mathrm{OR}=0.397,95 \% \mathrm{CI}=0.076-2.070)$.

In total, 11 patients $(11 \%)$ required only Non-invasive ventilation (NIV) during ICU stay. The overall mortality for patients was $1 \%$. In Group C, 4 patients (4\%) required NIV, of which 0 patients $(0 \%)$ died, while $7(7 \%)$ patients in Group G required NIV of which $1(1 \%)$ died. NIV was associated with better outcome and lesser mortality in both groups $(\mathrm{P}=0.002, \mathrm{OR}=0.154,95 \% \mathrm{CI} 0.042-0.567)$.

The SOFA score $(11.77 \pm 2.93)$ were significantly higher in non-survivors in the study $(\mathrm{P}<0.05)$ as shown in [Table 4]. The SOFA score in survivors was $5.375 \pm 2.85$.

Table 4:- SOFA scores as predictors of mortality

\begin{tabular}{|l|l|l|l|l|l|}
\hline & Outcome & $\mathrm{N}(\%)$ & Mean & Std. Deviation & Std. Error Mean \\
\hline ALOS & survivor & 56 & 12.143 & 25.29 & 3.38 \\
\hline & Non-survivor & 44 & 5.709 & 6.16 & 0.92 \\
\hline SOFA & survivor & 56 & 5.375 & 2.85 & 0.38 \\
\hline & Non-survivor & 44 & 11.773 & 2.93 & 0.44 \\
\hline
\end{tabular}

In Group G, Platelet count $<150$ (score of 1 on SOFA score) was present in 28 patients $(57.14 \%$ ) out of which 22 Patients $(78.57 \%)$ died. Hence, platelet count $<150$ can be used as a simple predictor of mortality in the elderly $(\mathrm{P}=$ $0.000, \mathrm{OR}=5.630,95 \% \mathrm{CI}=2.362-13.420$ ) (Table 5).

Table 5:- Platelet count as predictor of mortality in elderly.

\begin{tabular}{|l|l|l|}
\hline Platelet Count & $\mathrm{N}(\%)$ & p-value \\
\hline Survivor & $06(21.43)$ & 0.000 \\
\cline { 1 - 2 } Non-Survivor & $22(78.57)$ & \\
\cline { 1 - 2 }
\end{tabular}

On univariate analysis of the ICU treatment modalities, it was observed that need for mechanical ventilation $(\mathrm{P}=$ $0.003)$ and inotropes $(P=0.018)$ were predictors of mortality in geriatric age group.

On applying the regression model by means of multivariate analysis, it was observed that the inotropic support was the only variable that independently discriminated ICU mortality $(\mathrm{P}=0.000)$.

\section{Discussion:-}

In our study we had $49 \%$ patients $>65$ years similar to Indian study by Sodhi et al [4] which had52\% patients $>65$ years. In the US study data,itvaried between $42 \%$ to $52 \%$ [5]. We found overall ICU mortality of $27 \%$ in our study subjects, with no difference between the control group and the geriatric population $(\mathrm{P}>0.05)$. Different studies in the literature have studied the association of age with the outcome in geriatric patients. Rosenthal et al. in a 
multihospital study of 38 ICUs found an age-related increase in mortality in 1,50,000 consecutive admissions [6]. However, many other studies could not establish a positive relationship between age and mortality. van den Noortgate et al. in their study in very elderly patients could not correlate age with greater in-hospital mortality [7]. Rockwood et al. in a two-center study on 1-year outcome observed that although ICU and 1-year mortality rates differed between $>65$ years and $<65$ years, but age was not a major contributor to the variance in outcome [8].deRooij et al., in a meta-analysis from 12 prospective and retrospective studies, also concluded that it is not age per se but factors such as severity of illness and premorbid functional status that are responsible for poor prognosis [9]. In a review by Boumendil et al., the authors commented that age itself explains only a small part of the increased hospital mortality, suggesting that specific information such as functional, cognitive, and nutritional status, as well as co-morbidities, should be collected to predict mortality in elderly ICU patients [10].Asa majority of studies conclude that age is not a major contributor towards mortality, treatment options should not vary with age and specific therapy should not be withheld for increasing age. However, It is not possible to define evidence-based recommendations for ICU admission of the elderly [10] In our study, we found no statistical difference in the treatment modalities offered to both the groups in the form of mechanical ventilation, inotropic support, renal replacement therapy or tracheostomy $(\mathrm{P}>0.05)$ [Table 3].

We found the ICU mortality in geriatric patients to be $27 \%$. Studies have reported the mortality rates in ICU patients varying from $3 \%$ to $64 \%$, depending upon the type of subjects studied. [15] Our study population comprised primarily of medical cases and the overall mortality corresponds roughly to that expected as per the SOFA scores.

We observed that mechanical ventilation and inotropes were significant treatment factors for ICU mortality in geriatric patients. However, on multivariate analysis only inotropic support was found to be independently associated with increased mortality. Mortality rate for our geriatric patients on mechanical ventilation was 58.8\%, which is similar to the previous studies in which overall mortality ranged between $41 \%$ and $78 \%$ [12],[13],[14],[15],[16]. In our study, we found that the odds of having survival in geriatric ICU patients on mechanical ventilation is 0.473.A Brazilian study in 199 elderly patients $>65$ years also found the need for mechanical ventilation as an independent determinant of mortality $(\mathrm{P}<0.001, \mathrm{OR}=3.57$, CI 95\% 1.24-10.3) [1].van den Noortgate et al. found mechanical ventilation as a factor associated with mortality $(\chi 2 ; \mathrm{P}=0.00005)$ [7].

We also found that the odds ratio in geriatric patients requiring inotropic support is $8.500(\mathrm{P}=0.000, \beta$ coefficient $=$ 1.221). Inotropic support has been associated with mortality in literature. van den Noortgate et al. in a study on 104 patients $>85$ years found inotropes as an independent risk factor of mortality $(\chi 2 ; \mathrm{P}=0.00001, \beta$-coefficient $=$ $0.9698)$ [7]. Friedrich et al. also associated use of inotropes or vasopressors with long-term ICU mortality $(\mathrm{OR}=$ 7.1, 95\% CI 2.6-19.3) [17].

In our study, 13 patients (13\%) required renal replacement therapy (RRT) and the mortality rate for patients requiring renal replacement was $69.23 \%$. A total of 8 patients $(8 \%)$ in Group C required RRT out of which 5 (62.5\%) expired while 5 patients (5\%) in Group G underwent RRT during their ICU stay, of which 4 died (80\%). Significant difference in mortality was observed in Groups $\mathrm{G}$ and $\mathrm{C}$ requiring RRT in ICU ( $\mathrm{P}=0.049, \mathrm{OR}=3.343$, 95\% CI $=0.955-11.707)$. These results are similar to other studies $(\mathrm{P}=0.543)$. Romao Junior in a series of 361 patients with acute renal failure (ARF) identified the need for dialysis as a poor prognostic factor in elderly patients with ARF [18].

We found no difference in outcomes of tracheostomised patients in two age groups in our study $(\mathrm{P}=0.259)$. Numerous studies in the literature support our findings. Ho et al., in an audit of characteristics and outcomes in 168 adult ICU patients with tracheostomies concluded that tracheostomy appears to be a relatively safe technique in the ICU population and is not associated with adverse outcomes[21].Frutos-Vivar et al. in a vast study in 361 ICUs across 12 countries observed that adjusting by other variables, tracheostomy was independently related with survival in the ICU $(\mathrm{OR}=2.22 ; 95 \% \mathrm{CI}, 1.72-2.86)$ but in-hospital mortality was similar with or without tracheostomy (39\% vs. $40 \%, \mathrm{P}=0.65)$. [22]

The SOFA score $(11.77 \pm 2.93)$ were significantly higher in non-survivors in the study $(\mathrm{P}<0.05)$ as shown in [Table 4]. The SOFA score in survivors was 5.375 \pm 2.85 . This is similar to previous studies [19]

In our study, in Group G, Platelet count $<150 \times 10^{9} / \mu$ l (score of 1 on SOFA score) was present in 28 patients (57.14\%) out of which 22 Patients (78.57\%) died (Table 5). Hence, platelet count $<150 \times 10^{9} / \mu 1$ can be used as a 
simple predictor of mortality in the elderly $(\mathrm{P}=0.000, \mathrm{OR}=5.630,95 \% \mathrm{CI}=2.362-13.420)$. This inference is similar to other studies. Thrombocytopenia is common in ICUs and is a simple and readily available marker for mortality, independent of and complementary to established severity of disease indices. [20]

Hence, in our study the ICU mortality rates were similar regardless of the age. However, mortality rates increased in the geriatric population requiring mechanical ventilation and inotropes during ICU stay. However, only inotropic support could be proposed as an independent risk factor for mortality in the geriatric population. Hence, the geriatric patients requiring mechanical ventilation and inotropic support in ICU should be prognosticated accordingly.

\section{Limitations:-}

A few limitations of our study need to be acknowledged. First, this is a retrospective, observational study, so both internal and external validity is relative and uncertain. Our analysis focused only on ICU mortality, and we did not examine mortality after discharge. We did not include information of baseline functional status and physiological parameters in our study as we wanted to especially study the impact of ICU treatment modalities and thrombocytopenia on geriatric mortality. We also did not assess the long-term mortality which could have modified our results. Finally, our study was limited to a small tertiary care hospital and this may limit the generalization of our findings to other hospital settings.

\section{References:-}

1. Stein FD, Barros RK, Feitosa FS, Toledo DO, Silva Junior JM, Isola AM, et al. Prognostic factors in elderly patients admitted in the intensive care unit. Rev Bras TerIntensiva 2009;21:255-61

2. Belayachi J, El khayari M, Dendane T, Madani N, Abidi K. Factors predicting mortality in elderly patients admitted to a Moroccan medical intensive care unit. South Afr J Crit Care 2012;28:22-7.

3. Hennessy D, Juzwishin K, Yergens D, Noseworthy T, Doig C. Outcomes of elderly survivors of intensive care: A review of the literature. Chest 2005;127:1764-74.

4. Sodhi K, Singla MK, Shrivastava A, Bansal N. Do Intensive Care Unit treatment modalities predict mortality in geriatric patients: An observational study from an Indian Intensive Care Unit. Indian J Crit Care Med 2014;18:789-95.

5. Marik PE. Management of the critically ill geriatric patient. Crit Care Med 2006;34:S176-82.

6. Rosenthal GE, Kaboli PJ, Barnett MJ, Sirio CA. Age and the risk of in-hospital death: Insights from a multihospital study of intensive care patients. J Am GeriatrSoc 2002;50:1205-12

7. van den Noortgate N, Vogelaers D, Afschrift M, Colardyn F. Intensive care for very elderly patients: Outcome and risk factors for in-hospital mortality. Age Ageing 1999;28:253-6

8. Rockwood K, Noseworthy TW, Gibney RT, Konopad E, Shustack A, Stollery D, et al. One-year outcome of elderly and young patients admitted to intensive care units. Crit Care Med 1993;21:687-91

9. deRooij SE, Abu-Hanna A, Levi M, de Jonge E. Factors that predict outcome of intensive care treatment in very elderly patients: A review. Crit Care 2005;9:R307-14

10. Boumendil A, Somme D, Garrouste-Orgeas M, Guidet B. Should elderly patients be admitted to the intensive care unit? Intensive Care Med 2007;33:1252-62

11. Sacanella E, Pérez-Castejón JM, Nicolás JM, Masanés F, Navarro M, Castro P, et al. Mortality in healthy elderly patients after ICU admission. Intensive Care Med 2009;35:550-5

12. Meinders AJ, van der Hoeven JG, Meinders AE. The outcome of prolonged mechanical ventilation in elderly patients: Are the efforts worthwhile? Age Ageing 1996;25:353-6.

13. Cohen IL, Lambrinos J, Fein IA. Mechanical ventilation for the elderly patient in intensive care. Incremental changes and benefits. JAMA 1993;269:1025-9.

14. Gracey DR, Naessens JM, Krishan I, Marsh HM. Hospital and posthospital survival in patients mechanically ventilated for more than 29 days. Chest 1992;101:211-4.

15. Labrinos J, Cohen IL, Fein IA. The impact of age on disposition for mechanically ventilated patients: An examination of 41926 patients. Chest 1992;102:S149.

16. Thoner J. Outcome and costs of intensive care. A follow-up study on patients requiring prolonged mechanical ventilation. ActaAnaesthesiolScand 1987;31:693-8.

17. Friedrich JO, Wilson G, Chant C. Long-term outcomes and clinical predictors of hospital mortality in very long stay intensive care unit patients: A cohort study. Crit Care 2006;10:R59.

18. Romão Junior JE, Haiashi AR, Vidonho Junior AF, Abensur H, Quintaes PS, Araújo MR, et al. Causes and prognosis of acute renal failure in elderly patients. Rev Assoc Med Bras 2000;46:212-7. 
19. Vincent JL, Moreno R, Takala J, Willatts S, De Mendonça A, Bruining H, Reinhart CK, Suter PM, Thijs LG (1996) The SOFA (Sepsis related organ failure assessment) score to describe organ dysfunction/failure. Intensive Care Med 22:707-710

20. Vanderschueren S; De Weerdt A et al: Thrombocytopenia and prognosis in intensive care. Critical Care Medicine. 28 (6): 1871-76, 2000

21. Ho YM, Wysocki AP, Hogan J, White H. An audit of characteristics and outcomes in adult intensive care patients following tracheostomy. Indian J Crit Care Med 2012;16:100-5.

22. Frutos-Vivar F, Esteban A, Apezteguía C, Anzueto A, Nightingale P, González M, et al. Outcome of mechanically ventilated patients who require a tracheostomy. Crit Care Med 2005;33:290-8. 